\title{
Monitoring and Evaluation and Institutional Performance
}

\section{A Case of Teacher Self Learning Academy Project on School's Academic Performance in Bugesera District}

\author{
Sindayigaya Guy Jean Marie Vianney* \\ Dr. Ngarambe Prudence, PhD** \\ Mr. Nyamweya Mongute Nathan*** \\ *MBA student, Mount Kenya University, Rwanda \\ ** Senior Lecturer, Mount Kenya University, Rwanda \\ *** Lecturer, Mount Kenya University, Rwanda \\ DOI: 10.29322/IJSRP.10.11.2020.p10745 \\ http://dx.doi.org/10.29322/IJSRP.10.11.2020.p10745
}

\begin{abstract}
The present study target was to investigate the impact of Project M\&E on institutions' performance from the view point of primary schools in Bugesera District. The project aims to improve learning outcomes for P5 and P6 pupils in 15 selected in Bugesera districts' primary schools. It seeks to do this by enhancing teaching and learning process quality in P5 and P6 with methods of innovation and technology so as to increase the content and teaching methodology of language teacher self-academy project monitoring and evaluation and its impact on school performance was analyzed and compared, considering performance of students. The researcher adopted the descriptive survey design. The study population comprised 956 in total including 300 teachers, 15 head teachers, 15 SEO's and 615 students of 15 primary schools in Bugesera district and 11 plan international officers. The researcher used simple randomly sampling to select the schools; hence 5 schools will be sampled. Simple Stratified sampling was used to categorize the sampled schools according to their zones and size. The researcher used the Yamane formula to determine the sample size of teachers, students and school administration, SEO's and Plan International Officers. And at each school level, the teachers were purposively sampled. The author used the questionnaire and interview to collect data. Data was analysed using SPSS 16.0. This study concluded that was a significant positive correlation between project monitoring and evaluation of school's activities and academic performance in English for P5\&P6 ( $r=0.715)$. Based on the findings for this study, the researcher concluded that project monitoring and evaluation greatly influenced academic performance in schools and that the TSLA project implementation process needs to be monitored and evaluated to enhance more efficiency. This is because most of the respondents $(81.7 \%)$ indicated that the teachers and students needs more resources for academic activities and TSLA should help them for their performance, lesson pan preparation, use of ICT and schemes of work, which are implementation practices of TSLA activities, increases academic performance in

This publication is licensed under Creative Commons Attribution CC BY.

http://dx.doi.org/10.29322/IJSRP.10.11.2020.p10745
\end{abstract}

English. From the research findings the researcher made the following recommendations: Project Monitoring and evaluation help the institution to perform better especially primary and secondary schools so TSLA projects coordinators and plan international should influence more the TSLA activities in the schools to enhance students' academic performance in Bugesera District .School management and SEO should audit every day activities to make follow up on TSLA's activities to raise students' academic performance.

Key Words: Monitoring: An evaluation: Academic' Performance: Project, Rwanda

\section{INTRODUCTION}

Social system of people that is well organized and well managed to meet the required needs and to achieve a common goal is called an institution. It is a strategic organization of people brought together to achieve some specific purpose; applies to all organizations, for profit as well as not for profit institutions. Common characteristics of an institution include: goals, structure and people. To achieve its goal, people within an organization plan and design different projects in a structured way. A significant quantity of time, effort, and other resources go into the development and implementation of projects (Alain, 2011).

A project involves temporarily efforts that are targeted to make products, results or services which are unique in terms of creativity and innovation. It requires well organized activities to establish and operate an effective project. A set of activities are carried out by different people as planned and agreed upon by project managers and other project stakeholders like participants, implementers, decision-makers as well as donors. All project stakeholders perform several but different major functions. These functions enable them to create a positive work environment and to provide the opportunities and incentives. In 
many projects, "monitoring and evaluation" is one of the pillars that support them for effective performance. Even though project planning is very essential, if not done in logical ways, a project may not achieve its desired outputs within its given timeframe. The best tools to use to ensure that the project is running smoothly or not is monitoring and evaluation (Thimoty, 2009). Therefore, M\&E is the main tool of management. Public institutions, private ones, civil societies, universities and research institutions should be aware of the effectiveness of their efforts, but the key question being asked is who must judge on the right basis and how to conduct M\&E effectively (Alain, 2011).

Monitoring and evaluation is the best method to check the progress of a project and to ensure that what is being done can meet the achievements that are expected. However, monitoring and evaluation are different but also designed to make assessment to the achievement of organization. Monitoring is strategic and long process from the beginning to the end of the project implementation. Contrary evaluation is done at a specific time to check the level at which objectives have been achieved (Alain, 2011).

The primary function of $\mathrm{M} \& \mathrm{E}$ is to give directions on how the activities should be done. Interacting with suitable data which can be accessed into usable, timely and relevant statistical information is necessary in monitoring and evaluation as in turn leads to experience (Global Fund, 2003). A well monitoring and evaluation model looks at situational analysis, problem identification, objectives, activities, strategies, contributions, outputs, outcomes as well as the impact of the project. The Teacher self-learning Academy (TSLA) project M\&E system will draw on Plan International's Programme Accountability and Learning System (PALS) and tools and techniques specific to the innovation and designed to demonstrate both the success of the intervention and provide a strong evidence base for Plan and others to learn from the innovation.

At the level of activities and outputs, project monitoring will focus on measuring three main components of the innovation: the effectiveness of the 'hardware' (that is, the iPods, their usability, reliability and sustainability); the effectiveness of the 'software' (the audio-visual content itself, including its relevance and accessibility); and the effectiveness of the learning and reflection meetings. The effective M\&E will bring about good impact on school's performance in Bugesera District

\section{Problem Statement}

For organizational members especially managers who spend much efforts in order to achieve the organizational goal, good performance is a target for all community members. Many activities are carried out within an organization including setting goals, objectives and strategies, preparing plans, budget and forecasts, implementation, monitoring and evaluating performance, making corrective adjustments as well as performance review. These activities are done to ensure good performance of the organization. Plans without monitoring and evaluation leads to non-performance or ineffective performance.

Management and supervision of project activities is done as monitoring, with the purpose to improve the way the project is being implemented. It is continuous action to gather data on the implementation of the project activities. Evaluation to the success of the project in attaining its results should have monitored continuously (NSDS, 2007).

Monitoring and evaluation in many organizations are used as a tool by donors. Donors are eager to be informed on how the money is being used in that way the project managers do monitoring and evaluation to justify the use of money from donors. However, the role of monitoring and evaluation must be considered as for the organization or the project to find out whether it is meeting its objectives.

Despite the many projects that promote education, quality of education is still a big problem. The rapid expansion of Rwanda's education system has come with many challenges. Quality of education remains the core challenge. It is in this line that Teacher -Self Academy project (TSLA) seeks to contribute in improving quality of education. The project will contribute to "effective teaching and learning" through the "use of appropriate technology in education" by supporting the professional development of teachers of English Language and Science to achieve improved learning outcomes for P5 and P6 students. In this case the Plan International implemented different projects in Bugesera district including TSLA Project. The TSLA project has many objectives for improving the teaching and learning process in primary schools. The long-term change that the initiative seeks to support is improved learning outcomes in English and Science for both girls and boys. The general objective of this research was to assess the TSLA Project Monitoring and evaluation on Schools' academic Performance in Bugesera District. The specific objectives that guided this research were

i) To analyze the effect of monitoring and evaluation on school's academic performance in Bugesera District.

ii) To examine the level of monitoring and evaluation to improve school's academic performance in Bugesera District.

iii) To evaluate the challenges facing project monitoring and evaluation in Teacher Self Learning Academy project ( TSLA) in Bugesera District

\section{THEORETICAL LITERATURE}

\subsection{Theoretical Literature}

Monitoring and evaluation ensure the present and future best management of a project, institution or organization. This helps to put the connection among past, present and future (Kusek \& Rist 2004). Both monitoring and evaluation's aspects are needed to be accountable and decisive about the project (Valadez \& Bamberger, 1994).

The donors budgeting the activities are supposed to control the process of monitoring and evaluation, this can be done by manager team and implementers. The validity of monitoring and evaluation written report depends on the seriousness, accountability and the experience of the evaluator (UNDP, Evaluation office, 2002).

According to UNDP in the book called Monitoring and Evaluation for Results, it helps to achieve effectively expected results. Performance is defined as progress towards and achievement of results. A good organization in any institution is the beginning of success as it leads to good results (Jody et al., 
2000). The private sectors, the government institutions, nongovernmental organisations are interested in good management for better results. As there is a great need of good achievement it is the reason why all institutions are interested in management and evaluation. Evolution in monitoring and evaluation has led to the shift from traditional to modern way of management. Any institution or organization can plan a project and implement it but the question that should be asked is "is it going to give us expected results".

To be able to identify what works well and what does not work well monitoring and evaluation is necessary. They also indicate under what conditions in different focus areas lessons learned should be shared at a global level, through communities of practice or monitoring and evaluation groups, for example. This requires that staff record and share the lessons they have acquired with others (Cotton, 1988). The part of project design should also be prepared in monitoring and evaluation (Janice, 2019), this should involve the construction of the baseline data which describe the 'what' as a problem to be solved and the objectives to be achieved.

$M \& E$ enhance the effectiveness of organization by addressing the relationship between past, present and future should be done by monitoring and evaluation. M\&E can identify what has been done well in the past and refer to it for the present and future.

Evaluation of comprehensive development framework of World Bank noted that monitoring and evaluation is the channel of most of donors to be aware of the progress of any financed project (World Bank, 2004). Monitoring and evaluation also brings changes in institutions. It deals with the overall achievement of the institutions mission (Crawford \& Bryce, 2003). Monitoring and evaluation is most important management tool of a project because it facilitates how to find out the necessary information about project, it improves relationships among the people implementing it, it helps to identify in advance the challenges encountered in implementation and mitigate them, and it provides information that facilitate to make report (Crawford \& Bryce, 2003).

\subsubsection{Results-based monitoring and evaluation}

Both government and non-governmental organisations need to make follow up in all planned project and policies (Holvoet \& Renard, 2007). Nowadays all institutions including the government need change in people's life, but the problem is to know whether this is being achieved. Are the programs, projects and policies leading to the expected results? How can prior failure become success? Is there any good starting baseline that is likely to lead us where we want to achieve? These are kinds of questions asked by all stakeholders all over the world and are busy striving to find answers to them.

Emphasis put on results caused the shift of emphasis on monitoring and evaluation. As the management of today looks at the final results rather than activities, is the reason why the monitoring and evaluation is also focused on achievement of results.

Generally, the monitoring and evaluation deals with the assessment and measurement of the performance of the project, program, and policies. Monitoring and evaluation is the tool to be aware of the products of the organization, how the This publication is licensed under Creative Commons Attribution CC BY. beneficiaries enjoy them and how it brings change to the beneficiaries (Janice, 2019). To be aware of the favorable and unfavorable performance of an organization is very important for its improvement and all these are identified through monitoring and evaluation. For this reason, monitoring and evaluation are recognized as the tool used to ensure the performance and expected results in any institution (Suji, 2008).

Shortages of enough budget and high expectations of results from the customers requires organizations to provide high quality services. The control of civil society and sometimes parliaments put pressure to the institutions functioning. In the same way the agency of aid requires the indicators of how the aid provided used.

Two, monitoring and evaluation also induces learning. The data rooted from monitoring and evaluation gives the aid agencies clear information (DAC Working Party on Aid Evaluation, 2001). The planning in the future are guided by the past experience.

The use of monitoring and evaluation is recommendable to the performance and sustainability of the institution.

Generally the increment of emphasizing on results influenced the system of management in different organisations. Monitoring and evaluation ensures the participatory approach in the system and team work spirit, hardworking, and good use of resources (Kusek and Rist, 2004).

\subsubsection{Challenges of Monitoring and Evaluation}

Measuring impact and challenges may take long time, it may cost much and the results are debatable. However, even if such challenges are encountered, this does not mean that M\&E should be neglected. It has to be done wisely with enough plan because if the challenges are not identified, there is no way to solve them (Callistus \& Clinton, 2016).

Lack of time reserved to discuss changes and any other results from monitoring and evaluation is also another challenge (Fals, 2001). Most of the time monitoring and evaluation are given little consideration and stakeholders are not able to get information about the aided project (Peter \& Hilary, 2001).

Challenging also is lack of adequate skills about how to implement the project, the ability to understand the objectives of the project toward achievement of them. M\&E system in TSLA was mainly based on measuring three main components of the innovation: the effectiveness of the 'hardware' (that is, the iPods, their usability, reliability and sustainability); the effectiveness of the 'software' (the audio-visual content itself, including its relevance and accessibility); and the effectiveness of the learning and reflection meetings. M\&E was challenged by teachers or implementers who do not know how to use the tools, students were not familiar with such teaching and learning system as well as inaccessibility of infrastructures like electricity in some schools. This method of teaching and learning helps in students' success hence good school performance (Plan International, 2014).

\subsubsection{Monitoring and evaluation in education}

Quality of education remains a core challenge in Rwanda. The factors underlying this are: a) the majority of teachers do not have sufficient English language skills (REAP, 2009) b) 
content: MINEDUC has identified poor skills in all areas of science and c) quality of education suffers from a lack of learner-centred methodologies.

Performance of schools is basically determined by teachers' performance through professionalism, hardworking and preparation of lesson plans (Onyeachu, 1996). The impact of teachers on the students' academic performance has become the common study of many researchers (Adediwuru \& Tayo; Aduand Olatundum, 2007; Lockhead \& dKomenan, 1988; Schacter\&Thum, 2004; Starr, 2002). Poor teachers' performance leads to poor students' academic performance (Ofoegbu, 2004) and the poor materials at school are also the factor that can affect the students' academic performance (Oredein, 2000).

\subsection{Empirical Review}

Because of the way the world is being globalized, all nations are striving to achieve international goals, to have political stability, security and faire for all the people so as to be most competitive among other countries in the world. Governments, parliaments, citizens, the private sector, the civil societies, the government, the non-governmental organizations, citizens and parliaments contribute to the better performance of the country. For this great demand of achievement, there is also demand for monitoring and evaluation.

The best tool that the government use to assess the achievement of the results is called monitoring and evaluation. As there is a need for the government to financial resources and hardworking there is also need for better results (Kuset \& Rist, 2004). M\&E facilitate to achieve good results. Specifically the aim of monitoring and evaluation is to measure the progress and take measure on the improvement of the implementation of project, policies or program. Like the emphasis part in the United
Nations development programs, the need for ensuring the better performance leads to emphasis of monitoring and evaluation (Kafmann, 2001).

In traditional way $M \& E$ is there to evaluate the amount of inputs and the process of implementation. Nowadays there is a focus to any contributing factor for the results. Among those factors include the policy makers, the implementers, the available resources, as well as the stakeholders. The basic objectives of monitoring and evaluation are: one, enhancing learning development of organizations, two, ensuring informed decision making, three, practical accountability; four, capacity building of the country in all areas.

\subsection{Theoretical Framework}

This research was guided by Systems Theory by Ludwig von Bertalanffy (1972) who is often cited as the father of general systems theory. The entire thing is more than just one of its part, one part is determined by the whole thing, and the small parts are connected to make the whole and it cannot stand alone and resist so as to be functioning well all the members should work as a system where one sustain and support another to achieve the common goal (Churchman, 2011).

This study was based on theoretical model developed by Shavelson McDowell and Oakes (1987). This model presents education system in terms of inputs, processes and outputs monitoring and evaluation. The inputs in this study may include TESLA project which comprises of the INSET for school academic performance.

Monitoring is good when it gives warning about what is not going smoothly. It also involves comparing what is achieved and what is expected to be achieved. An example is when there is a comparison between the results and the objectives set to be achieved in certain period of time.

\subsection{Conceptual Framework}

Independent Variable:

Monitoring and Evaluation

M\&E decisions' implementation

$>$ Quality control for compliance

$>$ Reporting non-compliance

$>$ Rework non-compliance
Dependent Variable: Institutional Performance

\section{Intervening Variables}

Figure 2.1: Conceptual framework

Source: Researcher, (2019)

Monitoring and evaluation is measured in terms of the inputs usage within an institution. Inputs involves different resources needed like human, financial resources as well as materials. For any phenomenon, the independent variable is the cause while the dependent variable is the outcome. Our above case the independent variables were the four projects, M\&E decisions' implementation, Quality control for compliance, reporting noncompliance, Rework non-compliance that might cause the change of dependent variable which is the institutional performance.

The intervening variable are the variables that act as a catalyst between independent and dependent variables. These variables are ones that have a strong contingent effect on the independent variable and dependent variables relationship. This is how their 
ISSN 2250-3153

presence modifies the original relationship between the independent and the dependent variables. In this case, Politics, The socio-cultural factors, Technology, infrastructure, Stakeholders involvement will indicate institutions' performance thus showing positive relationship between M\&E and Performance.

\section{RESEARCH METHODOLOGY}

\subsection{Research design and Population}

De Vaus (2001) stated that research design is that plan and structural investigation aimed at finding out the solutions to the questions of research. A descriptive research design was used to examine the impact of monitoring and evaluation on institutions' performance. It helps to specify clearly what the researcher wants to find out and the way of doing it. Under this research both quantitative and qualitative techniques and methods were used. According to Kothari (2004), the design must be rigid, must make enough provision for protection against bias and must maximize reliability.

Mugenda and Mugenda (2003) stated that population is totality of persons from which samples are taken for measurement. The total number of primary schools in Bugesera District is 79 schools. Among these the target population of 15 primary schools was used and totaled to 956 respondents made up of 15 head teachers, 300 teachers, 615 students, 11 Plan International staff and 15 sector educational officers (SEOs).

\subsection{Sampling design}

Williams (2009) defines a sample size as a number or objects in the sample. Sample itself is defined as all the population or case selected to take part in the research study. The researcher chose the zone purposively and uses simple randomly sampling to select the schools in Bugesera District. Stratified sampling was used to select school administration, teachers and students. Stratified sampling gave all schools equal chance to participate in the study.

According to Mugenda and Mugenda (2008), at least 10\% of accessible population is enough for descriptive survey study. The five selected schools were G.S Nyamata catholique, G.S Ntarama, G.S Rango, G.S Rilima and G.S Twimpala. The 5 head teachers of school heads of selected schools was purposefully selected to yield 15 head teachers. In this study the sample therefore comprised of 282 respondents, means that 181 represented students who study in P5 and P6 from 5 schools, 88 TSLA teachers from different schools of Bugesera District, 5 head teachers, 3 Plan International employees (TSLA project Manager) and 5 sector education officers. In this study, a stratified random sampling was conducted to gather quality data. According to Taherdoost (2016), stratified random sampling is convenient where the population under study is composed of subgroups and is of heterogeneous characteristics.
The number of respondents was determined using the Yamane formula (1967).

$$
n=\frac{N}{1+N e^{2}}=\frac{956}{1+956 * 0.05^{2}} \approx 282
$$

$\mathbf{N}$ : stands for the target population/ population size of the study $\mathbf{e}:$ is the level of precision equals to $(5 \%)$

n: Sample size

Table 1: Targeted population and sample size

\begin{tabular}{l|ccc}
\hline $\begin{array}{l}\text { Group of } \\
\text { respondents }\end{array}$ & $\begin{array}{c}\text { Targeted } \\
\text { population }\end{array}$ & $\begin{array}{c}\text { Percentage } \\
(\%)\end{array}$ & $\begin{array}{c}\text { Sample } \\
\text { size }\end{array}$ \\
\hline Head teachers & 15 & 1.57 & 5 \\
Teachers & 300 & 31.38 & 88 \\
Students & 615 & 64.33 & 181 \\
SEO & 15 & 1.57 & 5 \\
Plan & 11 & 1.15 & 3 \\
International & & & \\
staff & & & \\
Total & $\mathbf{9 5 6}$ & $\mathbf{1 0 0}$ & $\mathbf{2 8 2}$ \\
\hline
\end{tabular}

Source: Researcher, 2019

\subsection{Data Collection and Analysis}

The primary data was collected from hand in hand project by using close ended questionnaires. Closed ended questionnaires are those questions set that require the respondents to select from a list of responses. The questionnaires were distributed at the selected population like students, head teachers, Education Officers as well as Plan International Officials.

Interviews were also conducted with key informants who have information on impact of monitoring and evaluation on institution performance. These included head teachers, Plan International staff, and sector education officer among other project beneficiaries.

The data (views) from respondents categorized into themes upon which detailed explanation was based. For making sure that all the answers are logically and coherently recorded to facilitate understanding of phenomenon and cross check the data collect, the processes of editing and coding was considered. Once data edited and coded, they were statistically treated and analyzed using Statistical Package for Social Sciences (SPSS) to produce results.

\section{RESEARCH FINDINGS AND DISCUSSIONS}

\subsection{Demographic Characteristics of Respondents}

The section shows the background of the respondents according to their categories such as age, education level, family status, gender. The total number of the respondents was 282 and they were made of 5 head teachers, 88 teachers, 181 students, 5 sector education officers and 3 plan officers. Out of 269 questionnaires distributed to teachers and students, 181 were filled and returned giving a return rate of $67.3 \%$. These were distributed across five different schools in five different sectors in Bugesera District.

Table 2: Gender of the Respondents

\begin{tabular}{llclccc}
\hline Gender & Students & Head teacher & Teachers & SEO & Plan off & Percentage \\
\hline Male & 74 & 4 & 48 & 5 & 2 & $47.16 \%$ \\
Female & 107 & 1 & 40 & 0 & 1 & $52.84 \%$ \\
\hline
\end{tabular}

Source: Field data, 2019 
ISSN 2250-3153

As shown in the Table 2 the respondents were given equal chance and the male were 133 of 282 equals $47.16 \%$ while female respondents were 149 of 282 equals to $52.84 \%$.This means that the fair gender representation was ensured by the researcher during the study.

\subsubsection{Professional Qualification of the respondents}

The study sought to find out the academic qualifications of respondents among the teachers, head teachers, sector education officer and plan international officers in the division. The findings from the study are recorded in Table 3 .

Table 3: Academic Qualification of the respondents

\begin{tabular}{lccc}
\hline Category & A Level & Diploma & Bachelors \\
\hline Teachers & 60 & 16 & 3 \\
SEO & 0 & 0 & 3 \\
Head teachers & 1 & 0 & 4 \\
Plan Officers & 0 & 0 & 3 \\
\hline
\end{tabular}

\section{Source: Field data, 2019}

The study established that majority of the respondents were qualified in education by their academic qualification. This means that they were quite qualified for handling issues related to the project monitoring and evaluation for institution performance.

\subsubsection{Teaching Experience}

The researcher was interested in finding out the experience of teachers handling implementation of competence based curriculum in the public secondary schools. The findings are indicated in Figure 2.

Table 4: Descriptive Statistics from the respondents about how the project monitoring and evaluation affect the school academic performance

Statements N Mean Stdev Variance

Understanding of TSLA project monitoring and evaluation

Monitoring and evaluation make students and teachers to adhere to the teaching and learning rules and regulations efficient and effectively implemented

TSLA Project Monitoring and evaluation lead to effective academic performance in your school

1814.652 .703

\section{Source: Researcher, 2019}

Table 4 shows that majority strongly agreed with the given statements followed by those who agreed as it is shown by a mean greater than 4 . However there was a significant difference between those who strongly agreed with the statement that teachers and students preparation of the how the monitoring and evaluation facilitate the academic performance through project implementation especially those project related to the academic activities, due to the shown standard deviation.

Table 5: Understanding of TSLA project monitoring and evaluation

\begin{tabular}{lcl}
\hline Responses & Frequency & Percent \\
\hline SD & 10 & 5.5 \\
D & 4 & 2.2 \\
N & 7 & 3.8 \\
A & 24 & 13.2 \\
SA & 135 & 74.7 \\
Total & 181 & 100.0 \\
\hline
\end{tabular}

$S D=$ Strongly Disagree, $D=$ Disagree, $N=$ Neutral, A=Agree, SA=Strongly Agree

\section{Source: Researcher, 2019}

The respondents presented that they agreed that project monitoring and evaluation affect positively to the academic performance in the primary schools. Table 5 indicate the perception of the students on their understanding of TSLA Project monitoring and evaluation toward the institutional performance, the majority of the respondents $(87.9 \%)$ indicated that they are agreed or strongly agreed that the projects are needed to their academic performance to be monitored and evaluated in their schools for the academic purpose as it is shown in Table 5.

Table 6: Monitoring and evaluation make students and teachers to adhere to the teaching and learning rules and regulations efficient and effectively implemented

\begin{tabular}{lll}
\hline Responses & Frequency & Percent \\
\hline SD & 2 & 1.1 \\
D & 3 & 1.6
\end{tabular}


ISSN 2250-3153

$\begin{array}{lll}\mathrm{N} & 3 & 1.6 \\ \mathrm{~A} & 40 & 22.0 \\ \text { SA } & 132 & 73.1 \\ \text { Total } & 181 & 100.0\end{array}$

\section{Source: Researcher, 2019}

Table 6 shows the responses on how the project monitoring and evaluation helps the students and teachers to perform their academic activities in teaching and learning process. The findings showed that $95.1 \%$ (SA and $\mathrm{A}$ ) agreed to the statements, $1.6 \%$ are neutral $(\mathrm{N})$ to the statement, $1.6 \%$ (D) disagreed to the statement and $1.1 \%$ strongly disagreed (SD) to the statement with this statement it. The results indicated that students they are aware of how project monitoring and evaluation facilitate students and teachers to adhere to the learning and teaching rules and regulations efficiently and effectively implemented.

Table 7: TSLA Project Monitoring and evaluation lead to effective academic performance

\begin{tabular}{lll}
\hline Responses & Frequency & Percent \\
\hline SD & 7 & 3.8 \\
$\mathrm{D}$ & 4 & 2.2 \\
$\mathrm{~N}$ & 1 & .5 \\
$\mathrm{~A}$ & 56 & 30.8 \\
$\mathrm{SD}$ & 113 & 62.1 \\
Total & 181 & 100.0
\end{tabular}

Source: Researcher, 2019

Table 7 shows that majority $(92.9 \%)$ agreed (SA and A) with the given statements, $3.8 \%$ strongly disagreed (SD), $2.2 \%$ disagreed (D) and $0.5 \%$ were neutral $(\mathrm{N})$ to the statement. However there was a significant difference between those who strongly agreed with the statement that teachers and students preparation of the how the monitoring and evaluation facilitate the academic performance through project implementation especially those project related to the academic activities, due to the shown standard deviation in Table 4.

According to the results from head teachers, teachers, plan international officer and SEO's through the discussion with them and the researchers, the majority of the respondents indicated that monitoring and evaluation affect positively the students' academic performance and especially the teachers showed their side by encouraging different project to be implemented in education because they were agreed that TSLA made the significance roles in academic activities the schools.

\subsubsection{Monitoring and evaluation to improve school's} academic performance

The second objective for this study was to evaluate the level of monitoring and evaluation to improve school's academic performance in Bugesera District. To achieve this objective the respondents were required first to indicate the extent to which they agreed with the statements given in Table 8, Table 9, Table 10 and Table 11.

Table 8: Monitoring and evaluation aims at creating an overview of the quality of education in the school

\begin{tabular}{lll}
\hline Response & Frequency & Percent \\
\hline SD & 7 & 3.8 \\
D & 15 & 8.2 \\
N & .1 & .5 \\
A & 22 & 12.0 \\
SA & 131 & 74.3 \\
Total & 181 & 100.0
\end{tabular}

Source: Researcher, 2019

Table 8 shows that majority of the respondents indicated that project monitoring and evaluation aims at creating an overview of the quality of education in schools. It facilitates better the students to perform better in the academic activities with the given statements This implies that monitoring and evaluation of the implementation of TSLA projects does influence academic performance of the learners a significantly.

Table 9: Descriptive Statistics of results from the respondents of second objectives

\begin{tabular}{lllll}
\hline & 1 & 2 & 3 & 4 \\
\hline $\mathrm{N}$ & 181 & 181 & 181 & 181 \\
Mean & 4.238 & 4.464 & 4.144 & 4.718 \\
$\begin{array}{l}\text { Std. Error } \\
\text { Mean }\end{array}$ & .099 & .0824 & .090 & .061 \\
Mode & 5.00 & 5.00 & 5.00 & 5.00 \\
Std. Deviation & 1.327 & 1.108 & 1.211 & .819 \\
Variance & 1.760 & 1.228 & 1.468 & .670 \\
Range & 4.00 & 4.00 & 4.00 & 4.00 \\
\hline
\end{tabular}

Source: Researcher, 2019

Statement 1 Quality of teachers influence the project monitoring and evaluation toward the students' academic performance

Statement 2 Monitoring and evaluation aims at creating an overview of the quality of education in the school

Statement 3 Monitoring and evaluation matches evidence against criteria, arrive at judgments and make those judgments known to stakeholders such as plan international

Statement 4 project monitoring and evaluation affect Professional development strengthens of students learning skills Table 9 displays the descriptive statistics for the four different statements used to obtain responses from the respondents. As shown in the table all the means were above 4 showing majority were in agreement with the statements.

Table 10: Monitoring and evaluation matches evidence against criteria, arrive at judgments and make those judgments known to stakeholders such as plan international

\begin{tabular}{lll}
\hline Response & Frequency & Percent \\
\hline SD & 14 & 7.7 \\
D & 9 & 4.9
\end{tabular}


ISSN 2250-3153

\begin{tabular}{lll}
$\mathrm{N}$ & 10 & 5.5 \\
$\mathrm{~A}$ & 52 & 28.4 \\
$\mathrm{SA}$ & 96 & 52.5 \\
Total & 181 & 100.0 \\
\hline
\end{tabular}

Source: Researcher, 2019

Table 10 reveals that most of the respondents, that is $90.9 \%$ agreed (SA and A) with the statement that monitoring and evaluation matches evidence against criteria, arrive at judgments and make judgments known to stakeholders. This implied that $\mathrm{M} \& \mathrm{E}$ is important source of information for all stakeholders especially those not directly involved with the daily running of the project. The results displayed in Table 9 regarding this statement shoed that there were divergent views since the standard deviation was 1.212.

Table 11: Project monitoring and evaluation affect Professional development strengthens of students learning skills

\begin{tabular}{lll}
\hline Response & Frequency & Percent \\
\hline SD & 5 & 2.7 \\
D & 3 & 1.6 \\
N & 3 & 1.6 \\
A & 16 & 8.7 \\
SA & 156 & 84.2 \\
Total & 181 & 100.0
\end{tabular}

Source: Researcher, 2019

Table 11 shows that majority (92.9\%) strongly agreed (SA and A) with the given statements, $2.7 \%$ strongly disagreed (SD), $1.6 \%$ disagreed (D) and $1.6 \%$ was neutral $(\mathrm{N})$ to the statement. However there was a significant difference between those who strongly agreed with the statement that teachers and students preparation of the how the monitoring and evaluation facilitate the academic performance through project implementation especially those project related to the academic activities. This is because the standard deviation in table 9 was 0.819 .

According to the results from the discussion of the researcher and head teachers, teachers, plan international officer and SEO's through the discussion of them and the researchers, the majority of the respondents indicated that monitoring and evaluation affect positively the students' academic performance and especially the teachers showed their side by encouraging different project to be implemented in education because they were agreed that TSLA made the significance roles in academic activities.

\subsubsection{Challenges facing project monitoring and evaluation in} Teacher Self in TSLA

The last objective for this study was to examine the challenges facing project monitoring and evaluation in Teacher Self Learning Academy project (TSLA). To achieve this objective the respondents were required first to indicate the extent to which they agreed with the statements given in Table 12, Table 13, Table 14 and Table 15.

Table 12: Descriptive Statistics of the results from respondents about the third objective

\begin{tabular}{|c|c|c|c|}
\hline & 1 & 2 & 3 \\
\hline $\mathrm{N}$ & 181 & 181 & 181 \\
\hline Mean & 4.138 & 4.254 & 4.746 \\
\hline $\begin{array}{l}\text { Std. Error } \\
\text { Mean }\end{array}$ & of .101 & .074 & .054 \\
\hline Mode & 5.00 & 5.00 & 5.00 \\
\hline Std. Deviation & 1.357 & .995 & .731 \\
\hline Variance & 1.842 & .991 & .535 \\
\hline Range & 4.00 & 4.00 & 4.00 \\
\hline
\end{tabular}

Source: Researcher, 2019

Statement 1: The school management help the project monitoring and evaluation to be implemented in your school

Statement 2: Project monitoring and evaluation helps me in teaching and learning process in my all subject

Statement 3: The project monitoring and evaluation help achers to be creative and innovative learner through the use of available resources.

Table 12 shows that most of the responses were in agreement since all the three statements had a mean score of more than 4 . This implied that majority of the respondents were in support of the second objective of this research.

Table 13: The school management help the project monitoring and evaluation to be implemented in your school

\begin{tabular}{lll}
\hline Response & Frequency & Percent \\
\hline SD & 18 & 9.9 \\
D & 12 & 6.6 \\
N & 11 & 6.1 \\
A & 26 & 14.4 \\
SA & 114 & 63.0 \\
Total & 181 & 100.0
\end{tabular}

Source: Researcher, 2019

Table 13 shows that majority of the respondents indicate that school management help in project monitoring and evaluation implementation in the schools. This revealed that even the management within the selected schools play a greater part in the implementation of project monitoring and evaluation. The findings in Table 12 shows that views were divergent among the respondents since the standard deviation was 1.357 .

Table 14: Project monitoring and evaluation helps me in teaching and learning process in my all subject

\begin{tabular}{lll}
\hline Response & Frequency & Percent \\
\hline SD & 8 & 4.4 \\
D & 5 & 2.8 \\
N & 9 & 5.0 \\
A & 70 & 38.7 \\
SA & 89 & 49.2
\end{tabular}




\begin{tabular}{lll}
\hline Response & Frequency & Percent \\
\hline SD & 8 & 4.4 \\
D & 5 & 2.8 \\
N & 9 & 5.0 \\
A & 70 & 38.7 \\
SA & 89 & 49.2 \\
Total & 181 & 100.0 \\
\hline
\end{tabular}

Source: Researcher, 2019

The results displayed in Table 14 show that $97.9 \%$ of the respondents were in agreement (SA and $\mathrm{A}$ ) that project $\mathrm{M} \& \mathrm{E}$ helps them in teaching and learning process. Only $4.4 \%$ of the respondents strongly disagree, $2.8 \%$ disagreed while $5 \%$ were neutral. The results showed that project M\&E facilitates better the students to perform better in the academic activities with the given statements.

Table 15 shows that majority (95.5\%) agreed (SA and A) with the given statements, $1.7 \%$ strongly disagreed (SD), $2.2 \%$ disagreed (D) and $0.6 \%$ neutral $(\mathrm{N})$ to the statement. There was no significant difference between those who agreed with the statement that teachers and students preparation of the how the monitoring and evaluation facilitate the academic performance through project implementation. This because the standard deviation obtained for this stamen was 0.731 as shown Table 12.

Table 16: Correlations of variables
Table 15: The project monitoring and evaluation help students and teachers to be creative and innovative learner through the use of available resources

\begin{tabular}{lll}
\hline Response & Frequency & Percent \\
\hline SD & 3 & 1.7 \\
D & 4 & 2.2 \\
SD & 1 & .6 \\
D & 20 & 11.0 \\
N & 153 & 84.5 \\
Total & 181 & 100.0 \\
\hline
\end{tabular}

Source: Researcher, 2019

From the results from the discussion head teachers, teachers, plan international officer and SEO's through the interview with them and the researcher, the majority of the respondents indicated that monitoring and evaluation affect positively the students' academic performance and especially the teachers showed their side by encouraging different project to be implemented in education because they were agreed that TSLA made the significance roles in academic activities the schools.

\subsubsection{The correlation between monitoring and evaluation} and institutional performance

The respondents were asked to give their views on the correlation between project monitoring and evaluation and institutional performance in TSLA Project.

\begin{tabular}{|c|c|c|c|}
\hline & & $\begin{array}{l}\text { project monitoring and } \\
\text { evaluation }\end{array}$ & institutional performance \\
\hline \multirow[t]{3}{*}{$\begin{array}{l}\text { project monitoring and } \\
\text { evaluation }\end{array}$} & $\begin{array}{l}\text { Pearson } \\
\text { Correlation }\end{array}$ & 1 & $.715^{* *}$ \\
\hline & Sig. (2-tailed) & & .000 \\
\hline & $\mathrm{N}$ & 181 & 181 \\
\hline \multirow[t]{3}{*}{ institutional performance } & $\begin{array}{l}\text { Pearson } \\
\text { Correlation }\end{array}$ & $.715^{* *}$ & 1 \\
\hline & Sig. (2-tailed) & .000 & \\
\hline & $\mathrm{N}$ & 181 & 181 \\
\hline
\end{tabular}

**. Correlation is significant at the 0.01 level (2-tailed).

Source: Researcher, 2019

The findings in Table 16 show that project monitoring and evaluation and institutional performance were correlated with the success of TSLA project. The correlation coefficients $\mathrm{r}=0.715$ was produced with $\mathrm{p}$-value of 000 of a 2 -tailed. The findings show strong positive and statistically significant correlation between the two variables. Therefore project monitoring and evaluation significantly improves institutional performance especially the primary schools in Bugesera District.

\section{CONCLUSION AND RECOMMENDATIONS}

Based on the findings for this study, the researcher concluded that the project monitoring and evaluation greatly influenced academic performance in schools and that the TSLA project implementation process needs monitored and evaluated to enhance more efficiency. This is because most of the respondents $(81.7 \%)$ indicate that the teachers and students needs more resources for academic activities and TSLA should help them for their performance, lesson pan preparation, use of ICT and schemes of work, which are implementation practices of TSLA activities, increases academic performance in English . Secondly, the school management significantly influenced the performance of English and that the management needs to be audited to suit the needs of TSLA projects. Thirdly, the study concluded that the teachers' professional development determines academic performance in English since this is one of requirements of the implementation of TSLA projects in schools. This is evident since there is a positive correlation $(r=$ 0.715 ) between project monitoring and evaluation and academic performance of the schools. Finally, the study concluded that there is a strong positive relationship $(\mathrm{r}=0.715)$ between instructional policy and planning and academic performance in English. It was established that majority of the responses $(62.1 \%)$ strongly agreed that project monitoring and evaluation 
of instructional policy and planning significantly influenced academic performance of English.

\subsection{Recommendations of the Study}

From the research findings the researcher made the following recommendations:

i) Project Monitoring and evaluation help the institution to perform better especially primary and secondary schools so TSLA projects coordinators and plan international should influence more the TSLA activities in the schools to enhance students the academic performance in Bugesera District

ii) School management and SEO may audit every day means to make follow up TSLA's activities to raise students academic performance

iii) Teacher and students to be monitored and evaluated to ensure that they benefit from the TSLA's activities for their teaching and learning process

iv) The ministry of education to hire and train more quality assurance and standards officers to conduct project monitoring and evaluation to enhance the quality of education with the help of NGOs in schools to ensure educational projects and programs are implemented to promote good academic performance of the learners.

\section{REFERENCE}

[1]. Adam,S. (2005). The dynamics of Socio-Economic Development. London: Kogan Press

[2]. Alain B. (1990). Research Methodology. Paris, Dalloz

[3]. Bhartat. (2010). Monitoring and evaluation toolkit for junior farmer field life schools. FAO. London

[4]. Callistus, T., \& Clinton, A. (2016). Evaluating barriers to effective implementation of project monitoring and evaluation in the Ghanaian construction industry. Procedia engineering, 164, 389-394.

[5]. Churchman. (2011).What teachers and head teachers think about inspection. Cambridge Journal of Education, 25(1), 45-52.

[6]. Clegg, D. \& Billington, S. (1994).Making the most of your inspection: Secondary. London, Falmer Press.

[7]. Cotton, K. (1988). Monitoring student learning in the classroom. Office of Educational Research and Improvement (OERI), U.S. Department of Education.

[8]. Crawford, P., \& Bryce, P. (2003). Project monitoring and evaluation: a method for enhancing the efficiency and effectiveness of aid project implementation. International journal of project management, 21(5), 363-373.

[9]. De Vaus, D. (2001). Research design in social research. Sage.

[10]. Elkins, C. (2006). Monitoring and Evaluation (M\&E) for Development in Peace-Precarious Situations. New York: San Diego.

[11]. Fals. (2001). Evaluation and Results Based Management. London: Cambridge press

[12]. Freeman,T. (2005). Issues and Options Paper on UN Country Level Evaluations. UNEG Working Group on Country-level Evaluations: New York.

[13]. Frick, T.(2004). Developing an educational system: Theory to improve student learning and the quality of life. Retrieved May 31, 2019 from http://www.indiana.edu/\%7Etedfrick

This publication is licensed under Creative Commons Attribution CC BY. http://dx.doi.org/10.29322/IJSRP.10.11.2020.p10745 /proposals/est2004.pdf

[14]. Holvoet, N., \& Renard, R. (2007). Monitoring and evaluation under the PRSP: Solid rock or quicksand?. Evaluation and Program Planning, 30(1), 6681.

[15]. Janice, G. (2009), The Performance to enhance M\&E Success; measuring business Excellence. London: Cambridge University Press

[16]. Jody, Z., Kusek, J.Z., Ray and Rist, R.C. (2000). "Making M\&E Matter-Get the Foundation Right." Evaluation Insights Journal.Paris

[17]. Kauffman, M. (2001). The USDA Forest Service National Stewardship Pilot Projects in the Pacific Northwest: The FY 2001 Report of the Pacific Northwest Regional Multi-party Monitoring and Evaluation. The Watershed Research and Training Center, Hayfork, CA.

[18]. Kothari, C. R. (2004). Research methodology: Methods and techniques. New Age International.

[19]. Ktouf, M. (1992). Methods of Social Research (2 ${ }^{\text {nd }}$ ed.) Paris, Illinois.

[20]. Kusek, J., \& Rist, R. (2004). Ten steps to a results-based monitoring and evaluation system: a handbook for development practitioners. The World Bank.

[21]. Mackay (2007). Teacher evaluation: A conceptual framework and examples of country practices. First Results from TALIS, OECD, Mexico City.

[22]. Maxwell. (2005). Building a Performance -Based Monitoring and evaluation system: The Challenges Facing Developing Countries, Evaluation Journal of Australasia.

[23]. Mugenda, M. \& Mugenda, A. (2003). Qualitative and quantitative approaches. Research Methods. Nairobi: Africa Center for technology studies (Acts) Press.

[24]. Ofoegbu. (2004).Management in education. Nairobi, Kenya: Educational Research and Publications (ERAP).

[25]. Peter, R. and Hilary, B. (2001). A systematic approach in monitoring and evaluation. California: Sage press.

[26]. Reed and David, (2006). Monitoring trends and development evaluation. New York: Prentice Hall.

[27]. Scharter. (2000). Multi-country cooperation around shared waters: The role of monitoring and evaluation. Global Environmental Change 14: 5-14

[28]. Taherdoost, H. (2016). Sampling methods in research methodology; how to choose a sampling technique for research. How to Choose a Sampling Technique for Research (April 10, 2016).

[29]. UNDP (2002). Handbook on Monitoring and Evaluation for Results. Evaluation Office, United Nations Development Programme: New York.

[30]. UNDP (2005). Monitoring \& Evaluation Workshop for Country Offices in Asia \& Pacific Region. Workshop Report. Evaluation Office, United Nations Development Programme: New York.

[31]. UNDP (2006). Evaluation Policy Statement (Draft). United Nations Development Programme: New York.

[32]. UNDP, (2006). Handbook on Monitoring and Evaluation for Results. UN: Millennium Development Goals Report 2006.

[33]. UNEG (2005a). Norms for Evaluation in the UN System. United Nations Evaluation Group. 
[34]. Valadez, J., \& Bamberger, M. (1994). Monitoring and evaluating social programs in developing countries: A handbook for policymakers, managers, and researchers. The World Bank.

[35]. Weiss, C.H. (2000). Theory-based evaluation: Theories of change for poverty reduction programs. In: Feinstein, $\mathrm{O}$. and Picciotto, R. (eds.), Evaluation and Poverty Reduction. Operations Evaluation Department, World Bank: Washington, DC.

[36]. Williams, D. (2000). Monitoring school performance for standard based reforms. www.infomaworld.com

[37]. Yamane, T. (1967). Elementary sampling theory $\backslash$ Taro Yamane (No. 04; QA276. 5, Y3.).

\section{Sindayigaya Guy Jean Marie Vianney (Correspondent} Author)

MBA student, Mount Kenya University, Rwanda

Email:

Dr. Ngarambe Prudence, PhD

Senior Lecturer, Mount Kenya University, Rwanda

Email:

Mr. Nyamweya Mongute Nathan Lecturer, Mount Kenya University, Rwanda Email: 